\title{
PROTEIN KINASES AS TARGETS FOR ANTI-PARASITIC CHEMOTHERAPY
}

\author{
CHRISTIAN DOERIG \\ INSERM team, Wellcome Centre for Molecular Parasitology, University of \\ Glasgow, 56 Dumbarton Road, Glasgow G11 6NU, Scotland, UK
}

Parasitic protozoa infecting humans have a staggering impact on public health, especially in the developing world. Furthermore, several protozoan species are major pathogens of domestic animals and have a considerable impact on food production, largely but not exclusively in developing countries. In many instances, the parasites have developed resistance against available chemotherapeutic agents, making the search for alternative drugs a priority [1]. In line with the current interest in protein kinases inhibitors as potential drugs against a variety of infectious and non-infectious diseases, the possibility that protein kinases may represent targets for novel anti-parasitic agents is being explored in a variety of protozoan parasites $[2,3]$.

Research into parasite protein kinases has benefited greatly from genome and EST sequencing projects, with the genomes of a few species fully sequenced (notably that of the human malaria parasite Plasmodium falciparum) and several more under way. The overall picture that emerged from research in this area shows (i) that protozoan parasites, expectedly, possess homologues of many of the serine/threonine protein kinase families found in other eukaryotes (but no gene encoding tyrosine kinases have yet been identified in these organisms), and (ii) that protein kinase-based regulatory networks similar to those found in higher Eukaryotes, such as some of the major signal transduction pathways and the cell cycle machinery, operate in these organisms. However, the phylogenetic isolation of parasitic protozoa is reflected by atypical structural and functional properties of many of their protein kinase homologues. Likewise, evidence is emerging, which suggests that the organisation of some otherwise well conserved signal transduction pathways is divergent in some parasitic species. Selected examples of such divergences drawn from a variety of protozoan parasites, concerning for instance the CDKs, and the MAPK and cyclic nucleotide pathways, will be discussed.

The differences between protein kinases of a parasite and their homologues in its host cell suggest that specific inhibition of the former can be achieved. The problem of the validation of these enzymes as drug targets will be discussed, with emphasis on gene knock-out and chemical genetics approaches as possible solutions. The development of anti-parasitic drugs based on protein kinase inhibition is being pursued following two avenues [2, 3]: one consists of screening chemical libraries on recombinant enzymes; several protein kinases from parasitic protozoa are now available for this approach, and preliminary results will be presented. The second approach relies on the identification of the molecular targets of kinase inhibitors which have previously been shown to 
display anti-parasitic properties. This has led to promising developments in a few instances, in particular regarding PKG as a drug target against Eimeria and Toxoplasma (Plasmodium-related organisms of considerable veterinary and medical importance, respectively; see ref. [4] and purvalanol B, a purine-based CDK inhibitor which appears to affect unexpected targets in several protozoan parasites [5]. The recent resolution of the structure of a Plasmodium protein kinase complexed with small inhibitory molecules (Holton, S. et al. Structures of $P$. falciparum PfPK5: testing the CDK regulation paradigm and mechanisms of small molecule inhibition, submitted) opens the way to a rational approach towards the design of anti-parasitic drugs based on kinase inhibition.

\section{REFERENCES}

1. http://www.who.int/tdr/index.html, http://www.malaria.org and links therein

2. Doerig, C., Meijer, L. and Mottram, J. Protein kinases as drug targets in parasitic protozoa. Trends. Parasitol. 18 (2002) 366-371.

3. Hammarton, T.C., Mottram' J.C. and Doerig, C. The cell cycle of parasitic protozoa: potential for chemotherapeutic exploitation. Prog. Cell Cycle Res. $\underline{5}$ (2003) 91-101.

4. Gurnett, A.M., Liberator, P.A., Dulski, P.M., Salowe, S.P., Donald, R.G., Anderson, J.W., Wiltsie, J., Diaz, C.A., Harris, G., Chang, B., DarkinRattray, S.J., Nare, B., Crumley, T., Blum, P.S., Misura, A.S., Tamas, T., Sardana, M.K., Yuan, J., Biftu, T. and Schmatz, D.M. Purification and molecular characterization of cGMP-dependent protein kinase from Apicomplexan parasites. A novel chemotherapeutic target. J. Biol. Chem. 277 (2002) 15913-15922.

5. Knockaert, M., Gray, N., Damiens, E., Grellier, P., Grant, K., Fergusson, D., Mottram, J., Soete, M., Dubremetz, J.-F., Le Roch, K., Doerig, C., Schultz, P.G. and Meijer, L. Intracellular targets of cyclin-dependent kinase inhibitors: Identification by affinity chromatography using immobilized inhibitors. Chem. Biol. 7 (2000) 411-422. 